\title{
Managing Chronic Diseases in the Slovak Republic: Futures Perspectives and Challenges
}

\section{J. Hicks (Jordan Hicks), B. Ramirez (Bernardo Ramirez)}

${ }^{1}$ University of Central Florida, College of Health and Public Affairs,

\section{E-mail address:}

jmhicks@knights.ucf.edu

\section{Reprint address:}

Jordan Hicks

University of Central Florida

College of Health and Public Affairs

Department of Health Management and Informatics

4364 Scorpius St., HPA2-210, Orlando, FL 32816-2205

USA

Source: Clinical Social Work and Health Intervention

Pages: $31-36$

Volume: 9

Issue: 1

\section{Reviewers:}

Paweł Czarnecki

Warsaw Management University, PL

Andrea Shahum

University of North Carolina at Chapel Hill School of Medicine, USA

\section{Key words:}

Chronic Care Management. Preventative Care. Patient Center Care. Cost Awareness.

\section{Publisher:}

International Society of Applied Preventive Medicine i-gap

CSWHI 2018; 9(1): 31 - 36; DOI 10.22359/cswhi_9_1_05 @ 2018 Clinical Social Work and Health Intervention

\section{Abstract:}

With populations continuing to age and costs for their care expected to increase, it has become more important than ever for healthcare professionals to acknowledge the need to be proactive instead of reactive with regard to chronic care. Like many other countries in Central and Eastern Europe, healthcare facilities in the Slovak Republic are better equipped for acute care rather than chronic illnesses. There is a need to 
adopt a chronic care model in the Slovak Republic and update a set of clinical guidelines to streamline the diagnosis and treatment of chronic illnesses. Updating organizational structure and procedures relating to chronic care management will allow healthcare professionals to save costs; develop patient centered care; educate the public on preventative methods. Creating a plan that centers on preventative and personalized medicine will help future generations in the Slovak Republic and hopefully reduce the prevalence of chronic diseases.

\section{Introduction}

The Slovak Republic's healthcare system makes health insurance affordable for its citizens. People who earn more pay more, and those who earn less pay less. This approach allows over $98 \%$ of the population to be covered by health insurance, which translates into the majority of the population being healthy. However, approximately $22 \%$ of the population suffers from common diseases, such as: cardiovascular diseases, diabetes, respiratory diseases, psychiatric diseases, infectious diseases and cancer (Kapalla, 2010). Countries around the world are seeing a similar trend of an increasing prevalence of chronic diseases. Chronic illnesses currently affect over $1 / 3$ of the European population and account for poor health and restricted activity. This translates into about $70-80 \%$ of European healthcare costs being spent on chronic care (Legido-Quigley, 2013). With this in mind, the Slovak Republic has an opportunity to implement new chronic care management techniques, such as predictive, preventative, and personalized medicine as well as the chronic care model.

The Slovak Republic is facing an aging population and a very low birth rate. The average age has increased to 39.6 years in 2013, which is 5.5 years more than 20 years ago. This pace of a rising life expectancy in the Slovak Republic is relatively slow, however it can be dangerous in conjunction with a birthrate of only 1.3 babies per mother.
(Minarechova_2015) This aging population could lead to an increased need for chronic disease management. In addition to the increase in average population age, lifestyle choices can have a large impact on population health and chronic illnesses. In the Slovak Republic, " $41 \%$ of the population smoke regularly or occasionally, and the consumption of the alcoholic drinks was 106.31 per inhabitant in the year 2008" (Kapalla, 2010 p.560). These choices can have a lasting impact on one's health and could lead to increased healthcare costs due to the treatment associated with chronic diseases.

\section{Chronic Care Conditions}

In 2011, there were 51,903 deaths in the Slovak Republic, and about half of these deaths were caused by chronic conditions (Loucka, 2014). The majority of the mortality in the Slovak Republic is associated with the following diseases: diseases of the circulatory system (53.4\%); neoplasms (22.6\%); diseases of the respiratory system $(6.0 \%)$; diseases of the digestive system (5.6\%) (Kapalla, 2010). These causes of death are related to the prevalence of chronic illnesses and the risks associated with them.

Place of death also plays an important role in the discussion of chronic illnesses. The majority of the population in the Slovak Republic would prefer to die at home. However, only $23 \%$ of Slovakians die at 
home and $62 \%$ of Slovakians suffering from chronic conditions die in the hospital (Loucka, 2014). Citizens in the Netherlands experience a much different proportion of end of life settings, where only about $30 \%$ of deaths relating to chronic conditions occur at the hospital. This can be due to a variety of factors, such as their developed nursing home care system. Overall, these statistics affirm that the majority of the population in the Slovak Republic is not having the end-oflife care they prefer. Investigating the place of death allows researchers to examine end of life policy and determine if patients are receiving the highest quality of care. Adjusting policies relating to home hospice care and other end of life settings would allow more Slovakians to die in their preferred setting.

Currently, the Slovak Republic does not offer many long-term care solutions. There are no nursing homes available to the public, and "care homes for older people or local variations of nursing homes usually do not have a physician on the staff and many GPs do not have enough experience with symptom management at the end of life" (Loucka, 2014). This lack of long-term care options can make taking care of those suffering from chronic illnesses difficult. Due to this, the responsibility of caring for someone diagnosed with a chronic disease often falls upon the family members: "These diseases by their nature are not easily cured and require long-term medical care. As a result, patients and their families need to adapt their lives in order to manage the disease" (Legido-Quigley, 2013). Providing constant care can result in direct and indirect costs such as pharmaceutical expenses and potential loss of income, respectively. Overall, these costs can put strain on a household's budget. To help avoid these costs, healthcare professionals should provide education on preventative measures that should be taken to avoid being diagnosed with a chronic disease. This education should include promoting a healthy lifestyle, living conditions, and nutrition. Applying these recommendations to people's everyday lives can make a substantial difference in preventing chronic diseases.

Acute care beds dominate the hospital infrastructure in the Slovak Republic: "Across Europe and increasingly the rest of the world, the economic costs of chronic illness dwarf the costs of acute illnesses, both for the healthcare system and for other stakeholders" (Gemmill, 2008). With this in mind, the Slovak Republic should focus on improving access to chronic care and longterm beds instead of acute care. "In 2007, there were 26,546 acute beds, 4,450 psychiatric beds and 4,403 long-term beds in Slovakia" (Szalay, 2011). This reliance on acute care is not conducive to the treatment of chronic illnesses. Due to this, health officials implemented a bed reduction plan to adjust the structure of both inpatient and outpatient providers. This plan resulted in acute beds being reduced and 6,000 beds being eliminated or transformed into chronic care beds. In addition, "three acute care hospitals were closed and several others transformed into almost exclusively chronic (long-term) care facilities" (Szalay, 2011). All of these measures have made treatment for chronic illnesses more accessible. However, there are still opportunities for improvement with regard to limiting the reliance on acute care. "Even though the number of acute beds has steadily declined, it was still among the highest in Europe in 2008" (Szalay, 2011). Health officials should continue to implement an acute bed reduction plan and work towards improving the accessibility to longterm care for their patients.

\section{Clinical Guidelines}

According to the World Health Organization, the Slovak Republic does not currently have an official basis for the development 
of clinical guidelines on chronic conditions. "The Institute of Preventive Medicine, with the support of the Slovakian Ministry of Health, was active in the field of clinical guidelines some years ago, producing the handbooks for diagnostic and therapeutic guidelines, including the most important and frequent chronic conditions" (Legido-Quigley, 2013). Unfortunately, these handbooks were last updated in 2002 and do not reflect current practices. Due to this, the Slovak Republic has an opportunity to create new guidelines and best practices in relation to chronic conditions. Developing national guidelines will help improve the delivery and quality of care given to patients. In addition, regulating strategies to improve care for chronically ill patients and coordinating all actors involved will ensure better patient health outcomes and effectiveness. The engagement of stakeholders is also critical when developing new clinical guidelines. "Depending on the context stakeholders can include representatives of professional organizations, service providers, the pharmaceutical industry and funding bodies; patients, their families and carers and patient representatives or organizations; academics or other experts; and other members of civil society" (Legido-Quigley, 2013). Promoting transparency with these stakeholders will help ensure the success and acceptance of the new guidelines.

Constructing updated guidelines relating to chronic disease management does not mean professionals should disregard the need for prevention. It is important for Physicians to be prepared when treating patients with chronic diseases. However, it is even more important for them to educate their patients on prevention techniques. To promote healthcare cost savings and healthier lifestyle choices, Physicians should implement a predictive, preventative, and personalized medicine (PPPM) strategy (Sadkovsky et al., 2014). Predictive techniques require
Physicians to conduct regular check-ups and screenings with their patients to try and foresee a medical complication in an apparently healthy person. Public health officials can also engage in predictive techniques by "monitoring the quality of the tap water, water reservoirs, concentration of the pollens in the air, nutrition and the food safety" (Kapalla, 2010). Predictive measures can help reduce overall healthcare spending by eliminating the potential costs associated with the treatment of chronic illnesses. In addition, they foster a strong doctor-patient relationship and promote constant communication.

\section{Preventive Care and Management Strategies}

Prevention programs are also used in chronic care management. These programs should focus on educating the public and healthcare professionals on "a healthy lifestyle, healthcare, healthy nutrition, reduction of the damages due to alcohol, drugs and tobacco products, prevention of injuries, healthy family, healthy working conditions, healthy living conditions, reduction of the incidence of the infectious diseases, reduction of the incidence of the non-infectious diseases, and physical activity" (Kapalla, 2010). These objectives work towards improving public health and the health of each individual citizen. Prevention education is a low-cost solution for reducing the prevalence of chronic illnesses. Healthcare providers should focus on promoting these programs to improve quality of care and ensure future cost savings.

The last strategy Physicians in the Slovak Republic would benefit from is personalized medicine. It is important for healthcare professionals to understand that "a patient does not care about the population statistics; the patient cares about the health of him- or herself and the health of 
the close relatives" (Kapalla, 2010). Due to this, Physicians need to focus on the personalized aspect of Medicine. An example of a personalized approach is the prescription of a drug with respect to the patient's metabolism and possible interactions with other drugs. Understanding a patient's family history and preferences will improve patient safety and satisfaction and help to ensure coordinated patient-centered care. of stakeholders: "Collaborative, integrated, and people-centered care provision is a way forward for sustainable and efficient care systems" (Nagyova, 2013). Focusing on this approach will ensure chronic disease patients are receiving the highest quality of care. In addition, a chronic care model can help lower healthcare costs and lessen the burden of chronic care management on patients and families.

Table 1: Essential Factors of Chronic Care Management.

\begin{tabular}{|l|l|}
\hline Factor & Details \\
\hline $\begin{array}{l}\text { Community } \\
\text { resources }\end{array}$ & $\begin{array}{l}\text { Provider organizations need to be linked with community-based resources, e.g. } \\
\text { senior centers, patient education classes, and self-help groups. }\end{array}$ \\
\hline $\begin{array}{l}\text { Healthcare } \\
\text { organization }\end{array}$ & $\begin{array}{l}\text { The culture, organizations, and mechanisms of the healthcare and provider } \\
\text { organizations must promote safe and high quality care. For instance, provider } \\
\text { reimbursement is an important influence on providers' incentives to improve } \\
\text { chronic care. }\end{array}$ \\
\hline $\begin{array}{l}\text { Self- } \\
\text { management } \\
\text { support }\end{array}$ & $\begin{array}{l}\text { Most patients can be taught to manage chronic illness through diet, exercise, self- } \\
\text { measurement of conditions (e.g. glucometers), and proper medication use, and } \\
\text { education can help patients routinely assess problems and accomplishments. }\end{array}$ \\
\hline $\begin{array}{l}\text { Decision } \\
\text { support }\end{array}$ & $\begin{array}{l}\text { The daily use of evidence-based guidelines is key, and providers can be supported } \\
\text { through physician education and daily reminders. }\end{array}$ \\
\hline $\begin{array}{l}\text { Delivery } \\
\text { system } \\
\text { redesign }\end{array}$ & $\begin{array}{l}\text { Delivery systems for chronic care must be separated from acute care by using } \\
\text { planned visits and case management of high-risk patients. This redesign also } \\
\text { involves creating practice teams with a clear division of labor. }\end{array}$ \\
\hline $\begin{array}{l}\text { Clinical } \\
\text { information } \\
\text { systems }\end{array}$ & $\begin{array}{l}\text { Electronic systems provide data for better management of chronic illness through: } \\
\text { (i) reminder systems to help primary care teams comply with practice guidelines, } \\
\text { (ii) feedback for physicians on performance measures (e.g. lipid levels), and (iii) } \\
\text { data registries for planning individual patient care and conducting population- } \\
\text { based care. }\end{array}$ \\
\hline
\end{tabular}

Source: Adapted from Gemmill, 2008

With regard to chronic care management, the Slovak Republic would benefit from adapting a chronic care model. A chronic care model aims to foster systemic change and focus on those who have the disease, yet also includes preventive strategies for those who do not. This model utilizes six factors in chronic illness management, which are described in Table 1. Management of chronic illnesses requires a long-term approach and active involvement from a range

\section{Conclusions}

The Slovak Republic has an opportunity to change how chronic illnesses are being diagnosed and treated. In particular, they would benefit from increasing longterm care options; reducing the reliance on acute care; updating clinical guidelines on chronic diseases; utilizing a PPPM strategy; implementing a chronic care model. These strategies aim to encourage strong 
Doctor-patient relationships and continuity and coordination throughout the healthcare system. In addition, it is important to educate Physicians and patients on the importance of prevention, with regard to public health and lifestyle choices. Applying these changes is expected to result in more interventions, increased patient safety, and overall improvements in population health.

\section{References}

1. GEMMILL M(2008) Research note: Chronic disease management in Europe. The London School of Economics and Political Sciences. European Commission. The Internet: http://citeseerx.ist.psu.edu/viewdoc/download?doi=10.1.1.619.4434\&rep=rep $1 \&$ type $=$ pdf.

2. KAPALLA M, KAPALLOVA D, TURECKK L (2010) An overview of the healthcare system in the Slovak Republic. The EPMA Journal, 1(4), 549-561. doi: 10.1007/s13167-010-0061.

3. LEGIDO-QUIGLEY H, PANTELI D, CAR, J, MCKEE M, BUSSE R (N.D.) (2013) Clinical guidelines for chronic conditions in the European Union. World Health Organization.

4. LOUCKA M, PAYNE SA, BREARLEY SG (2014) Place of death in the Czech Republic and Slovakia: a population based comparative study using death certificates data. BMC Palliative Care, 13, 13. doi. org/10.1186/1472-684X-13-13.

5. MINARECHOVA R (2015, April 09) Study highlights Slovakia's aging population. Retrieved September 13, 2016, from The Slovak Spectator, http://spectator.sme. sk/c/20056850/study-highlights-slovakias-aging-population.html.

6. NAGYOVA I (2013) An Optimal Framework for Chronic Condition Management in Europe. Microbial Ecology In Health \& Disease 2413. doi:10.3402/mehd.v24i0.23078.

7. SADKOVSKY A, GOLUBNITSCHAJA O, MANDRIK MA, STUDNEV, MA, ABE H, SCHROEDER, H, ANTONOVA EN, BETSOU F, BODROVA TA, PAYNE K, SUCHKOV SV (2014) PPPM (Predictive, Preventive and Personalized Medicine) as a New Model of the National and International Healthcare Services and Thus a Promising Strategy to Present a Disease: From Basics to Practice. International Journal of Clinical Medicine 5,855-870. Doi.org/10.4236/ijcm 2014.514115.

8. SZALAYT, PAZITNY P, SZALAYOVA A, FRISOVA S, MORVAY K, PETROVIC M, VAN GINNEKEN E (2011) Slovakia: Health system review. Health Systems in Transition, 2011; 13(2):1-200. 